\title{
Energy saving smart waste segregation and notification system
}

\author{
Supriya Sarker \\ Dept. of Computer Science \& \\ Engineering \\ Chittagong University of Engineering \\ \& Technology \\ Chittagong, Bangladesh \\ sarkersupriya7@gmail.com \\ Dipta Sikder \\ Dept. of Electrical and Electronic \\ Engineering \\ World University of Bangladesh \\ Dhaka, Bangladesh \\ diptasikder775@gmail.com
}

\author{
Md. Sajedur Rahman \\ Dept. of Electrical and Electronic \\ Engineering \\ World University of Bangladesh \\ Dhaka, Bangladesh \\ sajid.peec.wub@gmail.com \\ Ashraful Alam \\ Dept. of Computer Science \& \\ Engineering \\ World University of Bangladesh \\ Dhaka, Bangladesh \\ ashrafulalam.wub@gmail.com
}

\author{
Md. Jahirul Islam \\ Dept. of Computer Science \& \\ Engineering \\ World University of Bangladesh \\ Dhaka, Bangladesh \\ johircse@gmail.com
}

\begin{abstract}
The increase in the generation of waste due to the continuous growth of urbanization and industrialization has become a severe problem for the government. Population density, lifestyles, economic conditions have a great impact on alarming waste composition. Hence, waste segregation is necessary to save our environment. The traditional manual method used for the segregation of waste in Bangladesh is time-consuming and can have adverse effects on the health of the involved people. Proper segregation can bring the economic values of the wastes as well. The proposed smart segregation system will notify the garbage boy after reaching the amount of waste at a certain level. If waste is not collected from that smart bin in time, the system will send a notification to the City Corporation. The proposed system will help to reduce the intensity of greenhouse gases as well. The system will consume electricity when an absence of sunlight, otherwise it consumes solar energy which saves energy consumption on sunny days.
\end{abstract}

Keywords - Internet of things (IoT), smart segregation, waste management, environment pollution, solar energy, smart bin

\section{INTRODUCTION}

With the accelerated growth of population and urbanization, the municipality garbage is increasing at the same rate. In the whole world, 2.01 billion tons of municipal solid waste is generated per year and at least $33 \%$ of that is not safely managed in an environment-friendly way. It is assumed that the amount will be 3.40 billion tons by 2050 . Expeditious growth of population is one of the crucial reasons for waste generation in the urban areas of the densely populated countries of Asia like Bangladesh [1]. According to the Bangladesh Waste Database 2014 [2], the percentages of the average composition of solid waste in different urban areas of Bangladesh are depicted in Fig. 1. Environmental pollution emerges from the garbage if it is being managed in an unsystematic and chaotic manner. The growing amount of waste and the necessity of more landfilling area has a vital impact on the emission of greenhouse gas in Bangladesh, hence, responsible for climate change [2]. The collection of waste is an essential step in managing wastes. Lack of awareness of city dwellers and proper planning and pledge of government have brought an alarming situation [1, 3]. Unfiltered dumping of solid waste is very common in urban

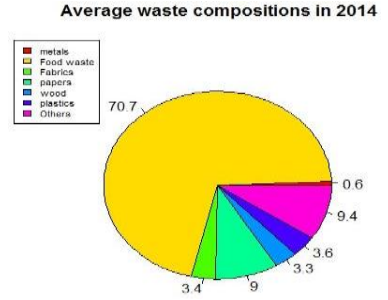

Fig. 1. Average waste composition in urban areas of Bangladesh in 2014

areas of Bangladesh which leads to severe environmental pollution [4]. The city corporation solid waste management system has an agreement to collect the waste regularly from every residence. However, staffs have apathy to doing their jobs regularly [3]. Therefore, a smart system should be implemented to resolve the current problem in Bangladesh.

There are some countries like Japan that use separate trash bins for wet and dry waste products and these areas are monitored by roadside surveillance cameras. In this way, people are being prevented from using the wrong bin. If the wrong bin is used, penalties are also imposed. In the case of urban areas of Bangladesh, people store their domestic wastes in an individual bin in every house. As every residence is not monitored by surveillance cameras, it is not possible to ensure that people store waste in an appropriate bin. Hence, automatic segregation at the residence level is very important for maintaining the quality of the recycled product produced from domestic waste.

Energy is a crucial need for attaining technological improvements all over the world. The annual energy consumption rate was approximately $15.6 \%, 13.8 \%, 13.6 \%$ in commercial, households, and manufacturing services, respectively. Hence, alternative energy preferences need to be considered. The need can be met by taking advantage of renewable energy sources. Solar energy can be a partial solution to the problem of scarcity of energy [5]. Bangladesh is situated in a favorable position to conserve solar energy [6, 7]. It is noted in [8] highest level of radiation is accessed from March to April and the least amount of radiation is 
accessed from December to January. Therefore, it is very necessary to the development of smart waste segregation and notification system which consume optimal energy.

A concise description of the existing approach is presented in Section 2. The proposed method including the structure of the smart bin and hardware setup is described in Section 3. The device prototype is shown and experimental results are analyzed in Section 4. The paper is being concluded in Section 5.

\section{EXISTING APPROACH}

From the literature reviewed, it is observed that an enormous system has been proposed and developed for an automated waste segregation system (AWS). In [9] an Automated Waste Segregator (AWS) system has been employed with a complex hardware architecture including parallel resonant impedance sensing mechanism and capacitive sensors to segregate dry, wet, and metallic wastes at the household level. In [10] an automatic system using programmable logic circuit has been presented in which infrared sensor, moisture, photo-electric, inductive, capacitive sensors, and hydraulic cylinders have been interconnected on the conveyor belt. However, at the initial stage of the system, a crusher has been used to reduce the amount of waste which might be degraded the quality of garbage and increase the possibility of mixed up of garbage. A DC gear-driven mobile unit was proposed in [11] which was controlled by the user with the help of a graphical user interface along with wifi interface provided by the Zigbee transceiver pair. In [12] a prototype was proposed to separate metal waste using programmable logic Controller. Sharanya et al. in [13] proposed a waste aggregation system using Arduino UNO. In the system, a prototype was developed using an IR proximity sensor for waste detection, moisture sensor for detecting the wet object, an inductive sensor for metal detection, and Laser LDR circuit for plastic and paper detection. In [14] a remote solid waste monitoring system has been proposed which implemented WIFI and GPRS module to store current waste status and location of the smart bin into the database, Pyroelectric sensor to monitor the motion of new garbage inside the smart bin, solar sensor to use solar energy as a source of energy, GSM module to send message to the garbage collector. However, the system fails as there is an inadequate supply of solar energy in the cloudy days, and hence the system is inappropriate for use in the rainy and winter season. Moreover, the proposed smart bin stores both dry and wet waste together which degrading the quality of reusability. In [15] the authors proposed an automatic metal, plastic and organic waste segregator system by implementing three ultrasonic sensors to measure the level of stored waste, inductive proximity sensor to separate metallic waste, blower to separate plastic and paper waste. The authors have assumed that plastic and paper wastes are lightweight compared to wet wastes and blown in the presence of highspeed blowers while wet wastes cannot. However, there are many types of wet wastes that are very lightweight compared to plastic, paper, or wood waste. Therefore, the rate of false detection of waste status will be increased. Most of the proposed systems are not appropriate for real-time use with garbage bin in our residence for their complex structure. Besides, they consume a certain amount of electricity for operation.
Hence, the major contribution made in this research is the development of a lightweight, economical, and environmentfriendly smart dry-wet waste segregation system that will segregate the household waste in the residential level using solar energy in presence of sunlight, otherwise other energy sources and to reduce environmental pollution, notify respective authority regarding the collection of garbage in due time. Therefore, the developed system facilitates the city corporation to monitor the management of garbage at the household level.

\section{Proposed Methodology}

This section explains the architecture and working procedure of the proposed system including the structure of the proposed smart bin.

\section{A. Structure of Proposed Smart Bin}

Our smart bin is divided into three horizontal layers, which are top, middle, and bottom layers. Fig. 2 shows the architecture of the smart bin. The top layer has a hole through which garbage will be thrown into the bin and a motion sensor mounted adjacent to the hole. The middle layer contains a rain sensor and servomotor. Two ultrasonic sensors are mounted in the bottom layer. The bottom layer is divided into two separate sections to contain wet and dry waste.

\section{B. Hardware Set Up}

We have set up both conventional AC current sources and solar energy systems. Due to the suitable geographical location of Bangladesh, there is ample sunlight from March month to September. Our proposed system can operate using solar energy on a sunny day. If solar power is not available due to rain or cloudy day, AC current will provide energy. The solar panel generates $12 \mathrm{v}$ DC current is being connected with the power supply board. Fig 3 demonstrates the block diagram of the system. From the power connector power source gets a supply of $220 \mathrm{v}$ AC. The power connector is connected with a transformer that converts the AC current into 12v DC current. A transformer is connected with the power supply board. In the board, a full-wave bridge rectifier will stabilize the noise and excessive current flow. The planted capacitor will store excessive current flow and release it over time. Voltage regulator IC will regulate the $12 \mathrm{v}$ current into $9 \mathrm{v}$. If the current flowing through the regulator IC is less than $9 \mathrm{v}$ in any case then the capacitor will release the stored current to give a backup current supply. The heat sink on top of the regulator will consume the excess heat and resist overheating of the regulator. The output current from the power supply board will flow in the micro-controller of Aurdino Uno [16]. The micro-controller power input system will convert the $9 \mathrm{v}$ current into $5 \mathrm{v}$ DC current.

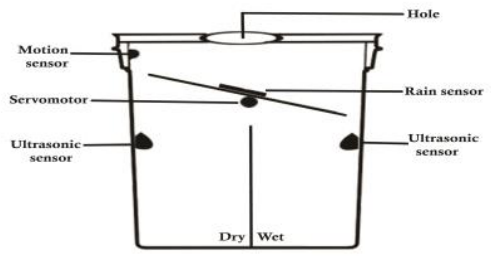

Fig. 2. Structure of the proposed smart bin 


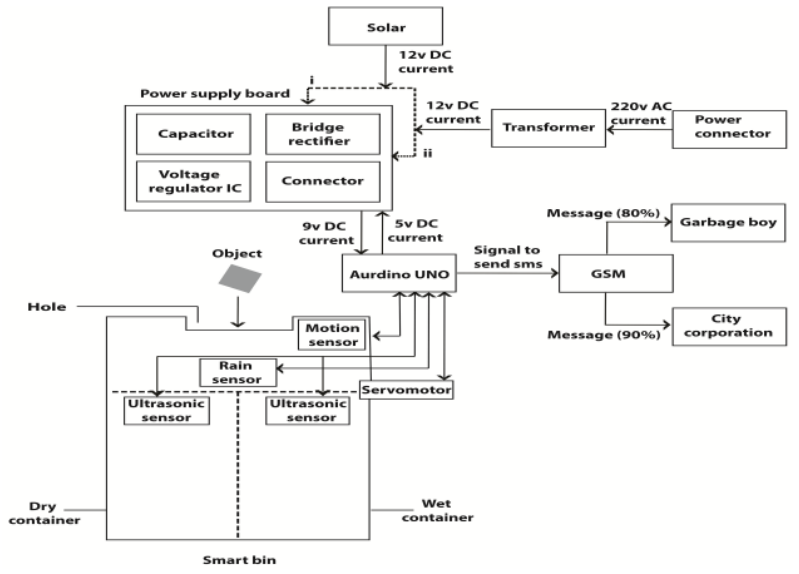

Fig. 3. Block diagram of the proposed system

From here 5v output current will be generated and it will be connected to the power supply board from where LCD display and GSM will get the input current flow. GSM, servomotor, rain sensor, ultrasonic sensor, motion sensor interfaces with the microcontroller through the wire.

\section{Architecture of the Proposed System}

The proposed system is divided into three modules, which are Object Detection Module, Level of Waste Detection Module, and Notification Generation Module. The modules are explained below:

1) Object Detection Module: A motion sensor is used adjacent to the hole of the garbage box which detects the motion of any object coming through the hole. By detecting motion, the motion sensor sends a signal to the rain sensor to measure the amount of moisture. If the moisture level is more than $30 \%$ then it will be considered as wet waste and if less than that the waste will be considered as dry. When the microcontroller confirms the type of waste, it will make the motion sensor move accordingly. If the waste is dry then the servomotor will rotate a degree of 90 left and send the garbage to the dry container, else it will rotate a degree of 90 to the right to send the garbage to the wet garbage container.

2) Level of Waste Detection Module: Two ultrasonic sensors measure the amount of waste in the two containers separately and continuously and send signals to the microcontroller. The microcontroller sends the signal to the LCD and the display will show the percentage of waste in the container.

3) Generation of Notification Module: Notifications from the segregator will mainly be generated by GSM. When the ultrasonic sensor detects that garbage has reached $80 \%$ of the total capacity of the container, it will send a signal to the microcontroller. The microcontroller will instruct GSM to generate a notification. Finally, it will transmit the notification with the location of the smart bin to the garbage-boy automatically. If the garbage-boy would not collect the garbage even after $90 \%$ of the total capacity of the smart bin then a message report will be automatically transmitted to the City Corporation.

\section{Results AND ANALYSIS}

The developed system has been implemented in the residence to test the system in real-time. This section illustrates the device prototype and lists the experimental data for some common household wastes.

\section{A. Device Prototype}

Fig. 4 demonstrate the whole prototype of the automated dry-wet waste segregation system and Fig. 5 shows the inner view of the smart bin. The white box is the proposed smart bin which contains a hole on the top of the smart bin, and motion sensor, rain sensor, ultrasonic sensor, and servomotor inside it.

\section{B. Experimental Data}

We have implemented the proposed system in residence in real-time. Table 1 lists the amount of moisture measured by rain sensor, type of objects, and degree and direction of the rotation angle of the servomotor for some common threshold wastes, mostly food waste. It has depicted in Fig. 1 that food waste is the most generated waste in 2014. In Table I, the segregation results of dry wet waste have demonstrated. Wet waste means organic wastes such as cucumber peel, banana peel, food waste, tea bag, etc. Dry waste includes paper wastes, wood, plastic bottles, cotton cloth, glass bottles, etc. The threshold value for the categorization of dry and wet is $30 \%$. As measured moisture value of stones, wood, batteries, tinned can, plastic bottles, glass bottles, polybags with vegetable peel by rain sensor garbage is lower than the threshold moisture value they are categorized as dry garbage. Similarly, the moisture measured in raw pumpkin peel, raw potato peel, raw orange peel, raw apple peel, paper, cotton clothes, tea bag, banana peel, cucumber peel by the rain sensor is higher than the threshold moisture value they are categorized as wet garbage. When vegetable peels in a polybag are thrown in the smart bin provides the wrong direction of rotation and detects as dry waste because it is a complex object.

A graphical representation of humidity variation of collected garbage objects is shown in Fig 6. It is clear from the graph that food waste especially vegetable and food waste contain most moisture ranging from $6 \%$ to $12 \%$ (object 1 to 7). Fig. 7 and Fig. 8 show the notification and address of residence which are sent to a garbage boy and to higher authority when $80 \%$ and $90 \%$ of the capacity of the smart bin is being full of garbage, respectively.
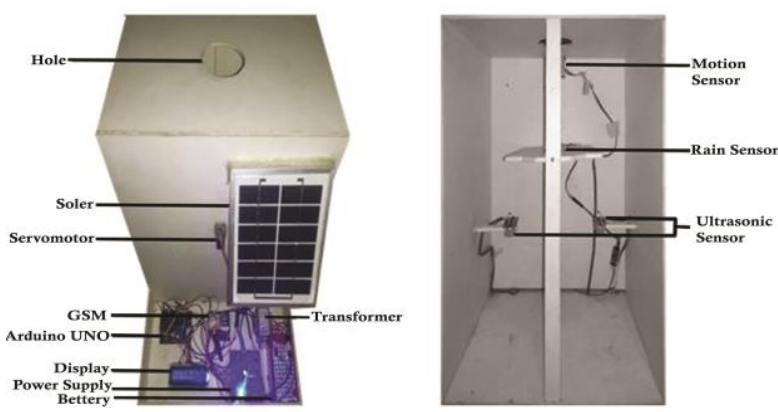

Fig. 4. Device prototype of Fig. 5. Inner view of the smart smart dry wet waste segregation bin system 
TABLE I. List of Detected Waste Status, Measured HUMIDITY AND DIRECTION OF ROTATION

\begin{tabular}{|c|c|c|c|c|}
\hline $\begin{array}{l}\text { Objec } \\
\text { t No. }\end{array}$ & Waste Name & $\begin{array}{c}\text { Humidity } \\
(\%)\end{array}$ & $\begin{array}{l}\text { Status } \\
\text { Detect } \\
\text { ed }\end{array}$ & $\begin{array}{c}\text { Wrong } \\
\text { Rotation }\end{array}$ \\
\hline 1 & Stones & 6.6 & Dry & No \\
\hline 2 & Wood & 12.7 & Dry & No \\
\hline 3 & Tinned Can & 18.5 & Dry & No \\
\hline 4 & Batteries & 20.3 & Dry & No \\
\hline 5 & $\begin{array}{l}\text { Polybags with } \\
\text { vegetable peel }\end{array}$ & 20.8 & Dry & Yes \\
\hline 6 & Plastic bottles & 22.9 & Dry & No \\
\hline 7 & Glass bottles & 27.6 & Dry & No \\
\hline 8 & Cotton clothes & 40.7 & Wet & No \\
\hline 9 & Paper & 45.3 & Wet & No \\
\hline 10 & Raw Apple peel & 83.5 & Wet & No \\
\hline 11 & Cucumber peel & 84.2 & Wet & No \\
\hline 12 & Raw Potato peel & 85.06 & Wet & No \\
\hline 13 & Raw Orange peel & 85.5 & Wet & No \\
\hline 14 & Banana peel & 86.2 & Wet & No \\
\hline 15 & Raw Pumpkin peel & 89.5 & Wet & No \\
\hline 16 & Tea Bag & 96.1 & Wet & No \\
\hline
\end{tabular}

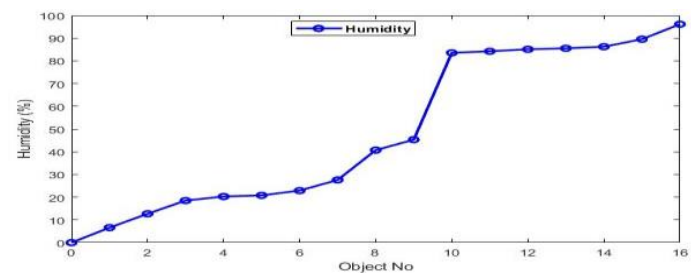

Fig. 6. Variation of humidity(\%) of various wastes

\section{CONCLUSION}

The proposed work aims to segregation of waste materials, in particular, wet and dry waste. The proposed system provides a viable solution to the current waste management problem which effectively segregates dry and wet waste. Segregation is a major and the most essential step of recycling. Proper segregation assures fewer wastes used for landfills, otherwise, by mixing organic wastes with soil generates methane. Methane is 25 times strong greenhouse gas than $\mathrm{CO} 2$. Wastes that are classified as wet (Object no. 8 to 16 in Table 1) can produce high-value compost by collecting and processing. This will reduce the amount of emission of greenhouse gases as well. Similarly, the wastes that are classified as dry (Object no. 1 to 7 in Table I) can be used as recycling items. The limitation of the system is it can segregate only one type of waste at a time with an assigned priority. When a set of garbage is thrown into the hole, the system cannot separate garbage from the packet considering the packet as a single object. When a complex set of garbage packet has been thrown into the smart bin, a robotic arm can be placed under the hole so that it can tear off the packet of

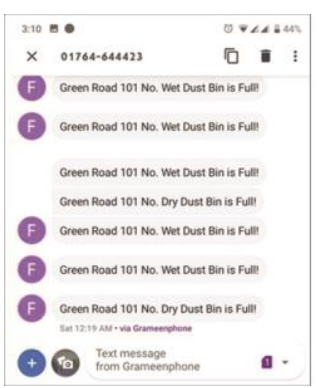

Fig. 7. Notification received by garbage boy

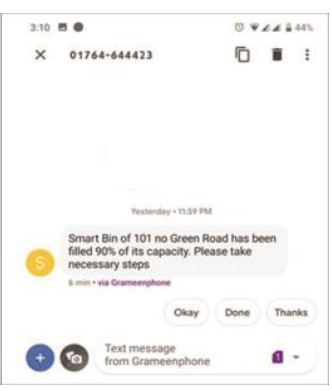

Fig. 8. Notification received by higher authority garbage so that rain sensor can measure the moisture of all the garbage separately. By using solar energy instead of conventional power source makes the system more environment-friendly and economical. Our notification system ensures the disposal of waste in time. Thus, the cleanliness program of the municipality becomes successful.

\section{REFERENCES}

[1] M. Alamgir, A. Ahsan, "Municipal solid waste and recovery potential: Bangladesh perspective," Journal of Environmental Health Science \& Engineering, vol. 4, pp. 67-76, 2007.

[2] Bangladesh Waste Database. (2014). Western Concern Technical Report Series.

[3] A. H. Mahmud. (2018). Dhaka Tribune. [Online]. Available: www.dhakatribune.com/opinion/special/2018/02/12/wastemanagement-projects-gone-waste Access 31-07-2019

[4] J. Johny, A. Joy, D. Sunny, B. M. Joseph, and S. M. Jamal, "Automatic Plastic Separating Technology For Solid Waste Disposal," Research and Development (IJCSEIERD), vol. 3, pp. 99108, Jun. 2013.

[5] F. Ahmed, A. Q. Al Amin, M. Hasanuzzaman, R. Saidur, "Alternative energy resources in Bangladesh and future prospect," Renewable and sustainable energy reviews, vol. 25, pp. 698-707, 2013.

[6] M. Mondal, A. Hossain, "Implications of renewable energy technologies in the Bangladesh power sector: long-term planning strategies," PhD diss., Universitäts-und Landesbibliothek Bonn, 2010.

[7] T. Jilani, K. Gomi, M. Yuzuku, "Low carbon society development towards 2025 in Bangladesh," in Proc. ICCEB'11, 2011.

[8] T. Islam, A. Neelim, "Climate change in Bangladesh: A closer look into temperature and rainfall data," Dhaka University Press, 2010.

[9] A. Chandramohan, J. Mendonca, N. R. Shankar, and N. U. Baheti, N. K. Krishnan, M. S. Suma, "Automated waste segregator," in Proc. 2014 Texas Instruments India Educators' Conference (TIIEC), 2014, pp. 1-6.

[10] R. M. Kittali, A. Sutagundar, "Automation of Waste Segregation System Using PLC," International Journal on Emerging Technologies, pp. 0975-8364, 2016.

[11] N. Sivakumar, A. R. Kunwar, S. K. Patel, and S. Kumar, "Design and development of an automatic clustered, assorted trash segregation system," in Proc. RTEICT'16, 2016, pp. 409-413.

[12] SM. Dudhal, B. S. Jonwal, H. P. Chaudhari, "Waste Segregation Using Programmable Logic Controller," International Journal For Technological Research In Engineering, vol. 1, 2014.

[13] A. Sharanya, U. Harika, N. Sriya, S. Kochuvila, "Automatic waste segregator," in Proc. ICACCI'17, 2017, pp. 1313-1319.

[14] N. Mohd Yusof, M. F. Zulkifli, M. Yusof , N. Y. Amira, A. A. Azman, "Smart Waste-Bin With Real-Time Monitoring System," International Journal Of Engineering And Technology, vol. 7, pp. 725-729, 2018.

[15] A. VJ, K. Balakrishnan, T. B. Rosmi, K. J. Swathy Krishna, S. Sreejith, T. D. Subha, "Automatic Waste Segregator and Monitoring System," Journal of Microcontroller Engineering and Applications, 2016.

[16] Arduino Uno Website. [Online]. 